\title{
Isolation of Escherichia coli and Its Associated Risk Factor from Diarrheic Children in Wolaita Sodo Town, Southern Ethiopia
}

\author{
Amanuel Wolde' \\ Yosef Deneke (iD) ${ }^{2}$ \\ Tesfaye Sisay ${ }^{3}$ \\ Mesfin Mathewos (D) ${ }^{4}$ \\ Haben Fesseha $\mathbb{D}^{4}$ \\ 'College of Agriculture, Department of \\ Veterinary Science, Jinka University, Jinka, \\ Ethiopia; ${ }^{2}$ School of Agriculture and \\ Veterinary Medicine, Jimma University, \\ Jimma, Ethiopia; ${ }^{3}$ Institute of \\ Biotechnology, Addis Ababa University, \\ Addis Ababa, Ethiopia; ${ }^{4}$ School of \\ Veterinary Medicine, Wolaita Sodo \\ University, Wolaita Sodo, Ethiopia
}

Correspondence: Mesfin Mathewos Email Aboseme23@wsu.edu.et
Introduction: Escherichia coli are among the major causes of mortality and morbidity in under-five children in developing nations including Ethiopia.

Methods: A non-analytical observational study design followed by a purposive sampling technique was conducted from October 2017 to June 2018, to isolate Escherichia coli and determine its associated risk factors from diarrheic children that were admitted to Christian hospital, Wolaita Sodo town. E. coli was confirmed using standard culture and biochemical analyses of the bacterium. In addition, a semi-structured questionnaire was provided to evaluate the potential risk factors that contribute to diarrhea in children.

Results: The overall isolation rate of $E$. coli in diarrheic children was $61.8 \%(68 / 110)(95 \%$ CI: $52.1-70.9 \%$ ). Factors such as age, contact with either animals or manure, negligence to handwashing before a meal with soap, and exclusive breastfeeding at six months $(p<0.05)$ has significant contribution to the prevalence of the $E$. coli in diarrheic children. The odds of being infected were highest in children whose caretakers had a habit of the negligence of handwashing before the meal (AOR $=6 ; 95 \%$ CI 30.8-49.8\%; $\mathrm{p}=0.01$ ).

Conclusion: Improving the hygienic practices amongst parents of children reduces its Escherichia coli occurrence. Furthermore, awareness of the importance of exclusive breastfeeding to parents of children should be maximized.

Keywords: children, diarrhea, Escherichia coli, risk factors, Wolaita Sodo

\section{Introduction}

In developing countries, children, particularly under the age of five years, are susceptible to diarrhea, which is one of the major causes of mortality and morbidity $^{1,2}$ and this also results in the annual death of nearly 2.6 million people worldwide, mostly from African children. ${ }^{3}$ Diarrhea is a common disease in children in most developing nations including Ethiopia. This is mainly related to consumption of contaminated foods, such as eating undercooked meat, unpasteurized milk, close relationship with reservoir animals, lack of handwashing with soap by the caregiver, lack of proper breast-feeding for children until the first six months and poor health infrastructure have been mainly related with bacterial pathogens that result in diarrheal disease. ${ }^{4-6}$

Infections (sepsis, pneumonia, tetanus, and diarrhea) and preterm delivery are responsible for 4 million neonatal deaths, according to a global review. ${ }^{7}$ Early beginning of breast-feeding (or human milk feeding) and exclusive nursing can avoid or decrease the negative consequences of both. ${ }^{4,5}$ 
The most genetically adaptable bacteria, E. coli, is the source of numerous plasmids and phage-mediated genes. Despite the fact that most of its members are nonpathogens that are found in the normal microflora of people and animals' intestinal tracts, some subsets of this bacterial species have acquired genes that allow them to cause intestinal or extraintestinal illness. ${ }^{8,9}$

Diarrhea syndromes can be caused by single or many etiologic agents, such as bacterial, viral, or parasite diseases. ${ }^{10}$ Among the causal agents are the following: Diarrheagenic E. coli (DEC) is the most frequent of the numerous enteropathogenic organisms, especially in poor countries and in diarrhea-related mortality in children under the age of five. ${ }^{11}$ The total isolation rate for E. coli from children under five years of age was $14 \%$ and $15.3 \%$ as reported by Adugna et $\mathrm{al}^{12}$ and Getaneh et $\mathrm{al}^{13}$ from a hospitalbased cross-sectional study at Bahir-Dar and Eastern Ethiopia, respectively. Other reports in Hawassa by Mulatu et al, ${ }^{14}$ in Bahir Dar by Yemane et al, ${ }^{15}$ in Jimma by Beyene et al, ${ }^{16}$ and in Ambo by Wagi ${ }^{17}$ indicated Campylobacter, Shigella, and Salmonella species, respectively.

Furthermore, the incidence and other epidemiological characteristics of these infections as causative agents of diarrhea differ from one region to the next, as well as across and among nations within the same geographical area. ${ }^{18}$ In the southern parts of the country, notably in the city of Wolaita Sodo, there is a scarcity of knowledge on the causes of diarrhea in children and the risk factors connected with it. As a result, the goal of this study was to estimate the prevalence of $E$. coli and its associated risk factors among under-five children who were hospitalized at Wolaita Sodo Christian Hospital in Southern Ethiopia.

\section{Materials and Methods Study Area}

The current research work was carried out in Wolaita Sodo town at Sodo Christian Hospital from October 2017 to June 2018. Wolaita Sodo is a town in the SNNPR situated 383 kilometers from Addis Ababa. The region is bordered on the north by Damot gale woreda, on the south by Humbo woreda, on the east by Damot Wilde woreda, and on the west by Damot Sore woreda (Figure 1). It has an annual rainfall of $100-1200 \mathrm{~mm}$ and a temperature of $25-35^{\circ} \mathrm{C}$. Its height ranges from 1650 to 2980 meters above sea level. The area is Woina-Dega (mid-altitude) at an elevation below 1600 feet, and the livestock population in the Wolaita Sodo zone includes 128,919 cattle, 29,191 sheep, 4606 equines, and 55,278 poultry. ${ }^{19}$ According to the results of the May 2007 housing and population census, Wolaita Sodo town has a population

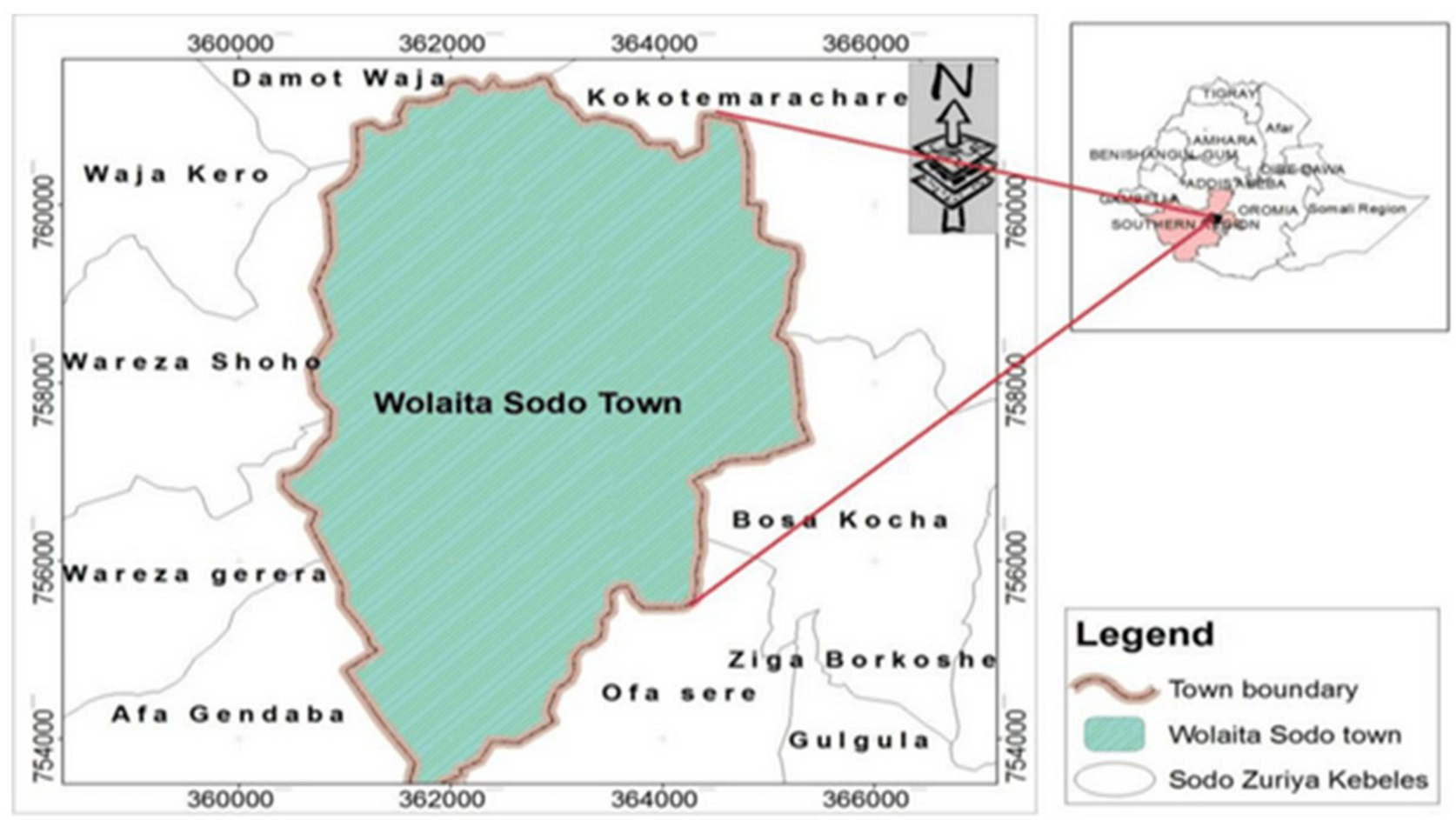

Figure I Map of the study area. 
of 102,922, with 54,315 men and 48,617 females, and a $5.3 \%$ annual population growth rate. This makes Wolaita Sodo the second most populous city in the South Region after Hawassa. Mixed farming, which includes the development of grain crops, cash crops, especially coffee, and animal production, is the most important economic activity. $^{20}$

\section{Study Population}

All under-five children with diarrhea who visited Sodo Christian hospital in Wolaita Sodo town were included in the study, as described by Black et al. ${ }^{19}$

\section{Inclusion and Exclusion Criteria \\ Inclusion Criteria}

Diarrheic children under the age of five who attended Sodo Christian Hospital with diarrhea and whose caregivers were willing to participate in the study were included in the study's sample population.

\section{Exclusion Criteria}

Diarrheic children over the age of five who had been on antibiotic medication for at least two weeks and whose caregivers refused to collect a sample were excluded from the research.

\section{Study Design and Sampling Methodology} Study Type, Type of Sampling, and Source of Samples A non-analytical observational study starting from October 2017 to June 2018 was conducted at the Sodo Christian Hospital found in Wolaita Sodo town. The Sodo Christian hospital was chosen purposefully, based on the availability of clinical cases (diarrheic youngsters) and the willingness of the children's parents. The pediatrician provided information about the children's health. Children with normal stool consistency and/or indications of dehydration, sunken eye, diarrhea, and weakness were categorized as healthy, whereas ill children with abnormal stool consistency and/or signs of dehydration, sunken eye, diarrhea, and weakness were classified as diarrhea. The kind, features, and color of diarrhea were also documented.

\section{Questionnaire Survey}

The childhood information was assessed by using a questionnaire survey. A semi-structured questionnaire was administered to parents or caretakers of the children to assess the general family life standard, ways of handling the children, and hygienic practices of the family during admission to the hospital. The questionnaires were designed in accordance with the study's aims and were prepared in a straightforward and easy-to-understand manner in order to obtain reliable information from the children's parents. The questionnaire covered all family practices that may have an influence on the correct management of the children's related risk factors for diarrhea. General health care, breastfeeding, hand cleaning, and illness prevention and control are among them.

\section{Sample Size Determination}

The selection of participants from Sodo Christian hospital and stool samples from children was based on a nonprobability purposive sampling technique. During sampling, the availability of clinical cases (diarrheic children) and the willingness of the parents of the children were the main factors considered to determine the total number of stool samples. Accordingly, 110 stool samples were collected from children who had diarrhea.

\section{Sample Collection Procedures}

The sample collection procedure was applied by medical laboratory technicians having the stool laboratory request of the pediatricians for diarrheic children under five years of age who visit Sodo Christian hospital. The stool samples were collected by researchers and were collected from diapers of the children. The collected stool samples were labeled properly and aseptically transported to the Wolaita Sodo regional veterinary laboratory in an icebox containing ice packs and then immediately processed for bacterial isolation.

\section{Isolation and Identification of Escherichia coli}

$E$. coli was isolated and identified based on the standard procedures described by Quinn et $\mathrm{al}^{21}$ and the techniques recommended by the ISO. ${ }^{22}$ After immediately arriving at the laboratory and/or overnight storage in the refrigerator at $40^{\circ} \mathrm{C}$ and thawing at room temperature, the samples were manually homogenized by using a vortex mixer for about 40 seconds. When there is a small quantity of samples in a sterile flask, $25 \mathrm{~g}$ of fecal samples were mixed into $225 \mathrm{~mL}$ of sterile buffered peptone water (Himedia, India) in a 1:9 ratio. The pre-enriched samples were homogenized in the flask for two minutes before being incubated aerobically for 24 hours at $370^{\circ} \mathrm{C}$. All the study's media were prepared according to the manufacturer's instructions.

The sample dilution of pre-enriched broth was inoculated aseptically onto sterile MacConkey agar (Himedia, India) and incubated at $37^{\circ} \mathrm{C}$ for 24 hours. The presence of growth on MacConkey agar was employed as the major criterion for 
moving on with $E$. coli isolation and identification. Suspected $E$. coli colonies were subcultured on Eosin methylene blue (EMB) agar medium (Himedia, India) to confirm their identity as E. coli. The green metallic sheen appearance of $E$. coli colonies on EMB was used to identify their features. For biochemical testing, all isolated colonies were maintained on a nutrient agar slant (Oxoid, England). Gram staining was used to evaluate the morphology and purity of all isolates ${ }^{23}$ and they were subjected to the standard biochemical tests: Indole test, Methyl red (MR), Voges Proskauer (VP) test, Citrate test, and triple sugar iron. The isolates that exhibited an IMViC pattern (++- -) were presumed to be $E$. coli isolates. $^{21}$ All the presumed $E$. coli isolates were subcultured on nutrient agar slant (Oxoid, England) for short-term preservation or maintenance.

\section{Data Analysis}

Discrete data (positive or negative for $E$. coli from diarrheic children of under the age of five) were subject to contingency table analysis, and Pearson's Chi-square test was used to determine the statistical significance of the relationships and/or associations between the dependent and independent variables from discrete data. To examine the relationship between each predictor variable and the result variable, a logistic regression analysis was used. The association was measured using crude odds ratios (CORs) for illness and 95\% confidence intervals for covariates. All the significant factors from the bivariate analysis were included in a multivariable analysis. This provided the Adjusted Odds Ratios (AORs) at a 95\% confidence interval. Multicollinearity diagnosis among independent variables by contingency coefficient was used to assess the model's suitability. The Hosmer and Lemeshow test was used to determine the model's goodness of fit to the data. Throughout the investigation, a significance level of $\mathrm{p}<$ 0.05 was employed. All data from the questionnaire survey and laboratory tests were coded, filtered, and recorded in Microsoft Excel spreadsheet 2007 (Microsoft Corporation) before being analyzed with SPSS version 20.0 software (SPSS INC. Chicago, IL).

\section{Ethical Considerations}

This study received ethical approval from the Wolaita Sodo University of Research Ethics and Review Committee. Before collecting the samples, the parents or guardians of the patients were asked for verbal agreement to collect samples from their children while adhering to stringent sanitary guidelines. All the studies were done in accordance with the Helsinki Declaration. The best practices for human care were followed, and the patients' parents or guardians were told of the study's objective and that the Wolaita Sodo University of Research Ethics and Review Committee authorized the oral informed consent process.

\section{Results \\ Overall Isolation of Escherichia coli from Diarrheic Children}

From a total of 110 stool samples from diarrheic children, 68 (61.8\%) (95\% CI: 52.1-70.9\%) were positive for Escherichia coli. The occurrence of E. coli in child diarrhea showed a significant difference by age $(\mathrm{p}=0.007)$, contact with either animal or manure $(\mathrm{p}=0.009)$, and exclusive breast-feeding in six months $(\mathrm{p}=0.036)$. A higher isolates of E. coli, 47 (42.8\%), was observed in children of age groups $>2$ years, $48(43.7 \%)$ in those who had a history of contact with either animals or manure, and $46(41.8 \%)$ in children who did not get only breast-feeding until six months of age. There was no significant difference in the occurrence of E. coli by sex (Table 1).

\section{Univariable and Multivariable Logistic Regression Analysis of Risk Factors Associated with Diarrhea in Children}

In the analysis of Risk factors concerning diarrhea in children independent variables like age, contact with either animals or manure, and exclusive breastfeeding at six months in univariable analysis were significantly associated with the occurrence of $E$. coli isolates $(\mathrm{p}<0.05)$. On the other hand, sex and negligence in handwashing before the meal was not significantly associated with E. coli isolates. To control confounders, the variables with $(\mathrm{p}<0.25)$ in the univariable logistic regression analysis were transferred to the multivariable logistic regression analysis. In multivariable logistic regression analysis, the occurrence of $E$. coli isolates in diarrheic children were more likely higher in age groups $>2$ years $(\mathrm{AOR}=2.4 ; 95 \%$ CI: $2.4(33-52.5 \%) ; \mathrm{p}=0.003)$ and children having a history of contact with either animal or manure $(\mathrm{AOR}=3.5 ;$ 95\% CI: 3.5 (34.2-53.4\%); $\mathrm{p}=0.001)$ than other age categories and in those having no history of contact with either animals or manure, respectively.

Similarly, children experiencing a habit of negligence to handwashing before the meal $(\mathrm{AOR}=6 ; 95 \% \mathrm{CI}: 6$ $(30.8-49.8 \%) ; \mathrm{p}=0.01)$ and those who did not get only 
Table I Overall Occurrence of E. coli with Different Risk Factors in Diarrheic Children

\begin{tabular}{|c|c|c|c|c|c|c|c|c|}
\hline Risk Factors & Category & No. Examined & No. Positive & $\begin{array}{l}\text { Category } \\
\text { Proportion (\%) }\end{array}$ & $\begin{array}{l}\text { Samples } \\
\text { Proportion (\%) }\end{array}$ & $\left(\chi^{2}\right)$ & $d f$ & $P$-value \\
\hline Age & $\begin{array}{l}\leq 2 \text { years } \\
>2 \text { years }\end{array}$ & $\begin{array}{l}49 \\
61\end{array}$ & $\begin{array}{l}21 \\
47\end{array}$ & $\begin{array}{l}42.8 \\
77\end{array}$ & $\begin{array}{l}19 \\
42.8\end{array}$ & 10.2 & 2 & 0.007 \\
\hline Sex & $\begin{array}{l}\text { Male } \\
\text { Female }\end{array}$ & $\begin{array}{l}62 \\
48\end{array}$ & $\begin{array}{l}38 \\
30\end{array}$ & $\begin{array}{l}61.3 \\
62.5\end{array}$ & $\begin{array}{l}34.5 \\
27.3\end{array}$ & 0.13 & I & 0.96 \\
\hline CAM & $\begin{array}{l}\text { Yes } \\
\text { No }\end{array}$ & $\begin{array}{l}73 \\
37\end{array}$ & $\begin{array}{l}48 \\
20\end{array}$ & $\begin{array}{l}65.7 \\
54\end{array}$ & $\begin{array}{l}43.7 \\
18.1\end{array}$ & 11.3 & I & 0.009 \\
\hline NHWBM & $\begin{array}{l}\text { Yes } \\
\text { No }\end{array}$ & $\begin{array}{l}63 \\
47\end{array}$ & $\begin{array}{l}44 \\
24\end{array}$ & $\begin{array}{l}69.8 \\
51\end{array}$ & $\begin{array}{l}40 \\
21.8\end{array}$ & 14.2 & I & 0.21 \\
\hline EBMF6M & $\begin{array}{l}\text { Yes } \\
\text { No }\end{array}$ & $\begin{array}{l}39 \\
71\end{array}$ & $\begin{array}{l}22 \\
46\end{array}$ & $\begin{array}{l}56.4 \\
64.8\end{array}$ & $\begin{array}{l}20 \\
41.8\end{array}$ & 13.5 & I & 0.036 \\
\hline
\end{tabular}

breastfeed in six months of age $(\mathrm{AOR}=5.6 ; 95 \% \mathrm{CI}: 5.6$ (32.5-51.6\%); $\mathrm{p}=0.02$ ) were more likely susceptible to E. coli infection than those who wash their hands and those who get only breastfeed in six months of age, respectively. There was no collinearity among the variables, and there was an insignificant difference between the observed and predicted values using $(\chi 2=1.24$; $\mathrm{p}=0.64$ ), which suited the data well (Table 2).

\section{Description of Socio-Demographic Situation Pattern Based on Questionnaire Survey Findings}

One hundred ten diarrheic children with ages below five years admitted to Sodo Christian hospital were considered. A semistructured questionnaire comprised contacts of manure or domestic animals in the house, breast milk feeding, treatment history of the child, and hand-washing practices were administered to caretakers/parents/based on their consent. Fifty-two
$(47.3 \%)$ out of 110 diarrheic children were females and 58 (52.7\%) were females-to-male ratio of 1.2:1. The age level of fewer than five years of which the highest number of participants $54(49 \%)$ is found in age groups above two years. Of all parents of the sampled children, $102(92.7 \%)$ used the toilet for defecation and the remainder were not in which children were susceptible to diarrheal infection because they did not pay attention to hygiene. Fifty-three (48.3\%) of the parents reared domestic animals in the home and $46(41.8 \%)$ used animal products as a supplement feed source.

\section{Discussion}

Diarrhea is a multifactorial disease since it is caused by interactions between the patient, its environment, diet, and infectious pathogens. ${ }^{24}$ As a result of this study's focus on E. coli, other microbiological, parasite, or management variables as a possible cause of infant diarrhea may be ruled out. The overall isolation rate of $E$. coli isolates was

Table 2 Risk Factors Associated with Escherichia coli Isolates in Diarrheic Children by Univariable and Multivariable Logistic Regression

\begin{tabular}{|c|c|c|c|c|c|c|c|}
\hline \multirow[t]{2}{*}{ Risk Factors } & \multirow[t]{2}{*}{ Category } & \multirow[t]{2}{*}{ No Examined } & \multirow[t]{2}{*}{ Samples Positive (\%) } & \multicolumn{2}{|c|}{ Univariable } & \multicolumn{2}{|c|}{ Multivariable } \\
\hline & & & & $P$-value & COR $(95 \% \mathrm{Cl})$ & $P$-value & AOR $(95 \% \mathrm{Cl})$ \\
\hline \multirow[t]{2}{*}{ Age } & $\leq 2$ years & 49 & $21(19)$ & & ${ }^{\circledR}$ & & (B) \\
\hline & $>2$ years & 61 & $47(42.8)$ & 0.007 & $2.9(34.2-53.8 \%)$ & 0.003 & $2.4(33-52.5 \%)$ \\
\hline \multirow[t]{2}{*}{ CAM } & Yes & 73 & $48(43.7)$ & 0.009 & $3.8(33.6-55.3 \%)$ & 0.001 & $3.5(34.2-53.4 \%)$ \\
\hline & No & 37 & $20(18.1)$ & & & & \\
\hline \multirow[t]{2}{*}{ NHWBM } & Yes & 63 & $44(40)$ & 0.21 & $4(32.0-52.4 \%)$ & 0.01 & $6(30.8-49.8 \%)$ \\
\hline & No & 47 & $24(21.8)$ & & ${ }^{\circledR}$ & & (®) \\
\hline \multirow[t]{2}{*}{ EBMF6M } & Yes & 39 & $22(20)$ & & ${ }^{\circledR}$ & & (8) \\
\hline & No & 71 & $46(4 I .8)$ & 0.036 & $6.8(31.5-49 \%)$ & 0.02 & $5.6(32.5-5 \mathrm{I} .6 \%)$ \\
\hline
\end{tabular}


$68(61.8 \%)$ out of 110 stool samples collected from diarrheic children. This result is higher when compared with the results of Adugna et $\mathrm{al}^{12}{ }^{12}$ Nguyen et $\mathrm{al}^{25}$ Mandomando et $\mathrm{al}^{26}$ Ansari et $\mathrm{al}^{27}$ who reported 48.3\% in Bahir Dar, 2.3\% in Nepal, 22.6\% in Mozambique, and $31 \%$ in Austria, respectively. However, it was found to be lower when compared to the findings of Shah et $\mathrm{al}^{28}$ $86.5 \%$ in Kenya and Ugwu et $\mathrm{al}^{29} 88 \%(23 / 26)$ in Nigeria. The difference in isolation rate might be attributed to different sociodemographic characteristics, sample size variation, and the season when the studies were carried out. ${ }^{30}$

In the present study, E. coli was isolated from diarrheic children of all age groups. Its occurrence was differed statistically by age $(\mathrm{p}<0.05)$. The odds of being diarrheic due to $E$. coli was more likely to occur in children above the age of two years. This finding agrees with a study conducted by Moyo et $\mathrm{al}^{31}$ in Tanzania and by Ansari et $\mathrm{al}^{27}$ in Nepal. This might be because maternal antibodies protect babies under the age of two years from severe diarrhea to some extent at first, and they appear to have developed sufficient immunity between the ages of 12 and 16 months. It can also be explained according to Sherchand, ${ }^{32}$ as children in this age range, are more interested in outdoor activities, careless about feeding themselves, and lack understanding about healthcare and personal cleanliness, all of which put them at risk for serious health problems as they get older. Therefore, this relatively higher chance of contact with either animals or their manure among higher children age groups than lower age groups could be a possible reason. There was a significant association $(\mathrm{p}<0.05)$ between the presence of $E$. coli in diarrheic children and a history of contact with animals or manure. This might be due to activities of small children in the vicinity of livestock and manure has a high probability of carrying $E$. coli because of the habit of hand contact with the mouth, eyes, and nose after touching the livestock and manure without wearing protective clothing and due to the negligence of hand-washing with soap that could be a vehicle for the occurrence of $E$. coli in children under five years of age.

The odds of diarrheic children who had a history of contact with either animals or manure were more likely to be diarrheic than those who did not have contact. According to a study conducted in Kenya by Edward et $a{ }^{33}$ children having contact with manure were independently associated with the occurrence of E. coli infectious diarrhea; farm residents and manure contacted children were significantly more likely to have diarrhea compared with non-farm resident children. Similarly, according to Radostits et al, ${ }^{34}$ a small number of E. coli pathogens in feces from cattle have the potential to infect humans, since children are vulnerable to be infected with $E$. coli through direct contact with calves, ingesting fecal contaminated food or water, and indirectly by contact with objects soiled with animal feces.

According to Aiello et $\mathrm{al}^{35}$ handwashing with soap could protect one out of three young children who suffered from diarrhea, and proper handwashing before meals and after defecation can lower exposure of children to enteric pathogens. The habit of the negligence of washing both hands with soap before feeding was significantly related to E. coli occurrence in diarrheic children. The odds of being infected with $E$. coli were observed to be more likely in children whose caretakers did not wash their hands with soap before feeding than those who washed their hands before feeding by soap. This agrees with the results of Sylvester et $\mathrm{al}^{36}$ in Bolivia and Adugna et $\mathrm{al}^{12}$ in Bahir Dar, indicating the likelihood of children being diarrheic whose caretakers have the habit of negligence to wash their hands.

In the present study, a significant $(\mathrm{p}<0.05)$ correlation was observed between exclusive breastfeeding practice of the mothers within the first six months and the isolation rate of $E$. coli from diarrheic children. Children who did not get exclusive breast milk feeding at six months of age were more likely to be susceptible to diarrhea due to E. coli than those children who were only provided with breast milk. This result is inconsistent with the study conducted in Kenya by Kageni, ${ }^{37}$ in which the number of diarrheic children was the least when complementary feeding was initiated after six months of age. In addition, the National Institute of Child Health and Development report, exclusive breast milk feeding supplies oligosaccharides and lactoferrin bioactive components for effective diarrhea prevention along with the nutritional components. Therefore, children should only be provided with their mother's breast milk for the first six months without any supplementary food items. ${ }^{38}$ In line with Adugna et al, ${ }^{12}$ the present study also revealed that the sex of the child has no significant impact on the occurrence of diarrhea due to $E$. coli.

\section{Conclusion}

The study finding of the current investigation revealed that there is a high proportion of $E$. coli isolates from under- 
five diarrheic children of the study area. Factors, such as age, breast milk feeding, the habit of washing hands without soap, and contact with manure in children were significantly correlated with the incidence of $E$. coli. Therefore, awareness creation to parents or caretakers of children on the importance of exclusive breastfeeding and personal hygiene is highly recommended.

\section{Abbreviations}

AOR, Adjusted odds ratio; COR, Crude odds ratios; CAM, Contact with either Animals or Manure; CI, Confidence Interval; $d f$, Degree of freedom; DEC, Diarrheic Escherichia coli; EBMF6M, Exclusive Breast Milk Feeding in Six Month; ISO, International Organization for standardization; NHW, Negligence to Hand Washing; NHWBM, Negligence to Hand Washing Before Meal; ${ }^{\circledR}$, Reference point; SNNPR, Southern Nation Nationalities and Peoples Region.

\section{Data Sharing Statement}

The datasets used and analyzed throughout the study will be provided by the corresponding author on reasonable request.

\section{Ethics Approval and Consent to Participate}

This study received ethical approval from the Wolaita Sodo University of Research Ethics and Review Committee. Before collecting the samples, the parents or guardians of the patients were asked for verbal agreement to collect samples from their children while adhering to stringent sanitary guidelines. All the studies were done in accordance with the Helsinki Declaration. The best practices for human care were followed, and the patients' parents or guardians were told of the study's objective and that the Wolaita Sodo University of Research Ethics and Review Committee authorized the oral informed consent process.

\section{Acknowledgments}

The authors would like to acknowledge the staff of Christian hospital, the institute of biotechnology, and Wolaita Sodo veterinary regional laboratory for their kind support during the research work.

\section{Author Contributions}

All authors made a significant contribution to the work reported, whether that is in the conception, study design, execution, acquisition of data, analysis, and interpretation, or in all these areas; took part in drafting, revising, or critically reviewing the article; gave final approval of the version to be published; have agreed on the journal to which the article has been submitted; and agree to be accountable for all aspects of the work.

\section{Funding}

This work was not funded by any source or institution.

\section{Disclosure}

All authors declared that they have no conflicts of interest in this work.

\section{References}

1. Boschi-Pinto C, Velebit L, Shibuya K. Estimating child mortality due to diarrhoea in developing countries. Bull World Health Organ. 2008;86:710-717. doi:10.2471/BLT.07.050054

2. Kosek M, Bern C, Guerrant RL. The global burden of diarrhoeal disease, as estimated from studies published between 1992 and 2000. Bull World Health Organ. 2003;81:197-204.

3. Vilchez S, Reyes D, Paniagua M, et al. Prevalence of diarrhoeagenic Escherichia coli in children from Leon, Nicaragua. J Med Microbiol. 2009;58:630-637. doi:10.1099/jmm.0.007369-0

4. Walker CLF, Rudan I, Liu L, et al. Global burden of childhood pneumonia and diarrhoea. Lancet. 2013;381:1405-1416. doi:10.1016/S0140-6736(13)60222-6

5. Liu L, Johnson HL, Cousens S, et al. Global, regional, and national causes of child mortality: an updated systematic analysis for 2010 with time trends since 2000. Lancet. 2012;379:2151-2161. doi:10.1016/S0140-6736(12)60560-1

6. Belongia EA, Chyou P-H, Greenlee RT, et al. Diarrhea incidence and farm-related risk factors for Escherichia coli O157:H7 and Campylobacter jejuni antibodies among rural children. $J$ Infect Dis. 2003;187:1460-1468. doi:10.1086/374622

7. Lawn JE, Wilczynska-Ketende K, Cousens SN. Estimating the causes of 4 million neonatal deaths in the year 2000. Int J Epidemiol. 2006;35:706-718. doi:10.1093/ije/dyl043

8. Abdalla M, Siham E, Suliman Y, et al. Microbial contamination of sheep carcasses at El Kadero slaughterhouse-Khartoum State. Sud $J$ Vet Sci Anim Husb. 2009;48:1-2.

9. Bélanger L, Garenaux A, Harel J, et al. Escherichia coli from animal reservoirs as a potential source of human extraintestinal pathogenic E. coli. FEMS Immunol Med Microbiol. 2011;62:1-10. doi:10.1111/ j.1574-695X.2011.00797.x

10. O'Ryan M, Prado V, Pickering LK. A millennium update on pediatric diarrheal illness in the developing world. Semin Pediatr Infect Dis. 2005;16:125-136. doi:10.1053/j.spid.2005.12.008

11. Viswanathan V, Hodges K, Hecht G. Enteric infection meets intestinal function: how bacterial pathogens cause diarrhoea. Nat Rev Microbiol. 2009;7:110-119. doi:10.1038/nrmicro2053

12. Adugna A, Kibret M, Abera B, et al. Antibiogram of E. coli serotypes isolated from children aged under five with acute diarrhea in Bahir Dar town. Afr Health Sci. 2015;15:656-664. doi:10.4314/ahs. v15i2.45

13. Getaneh DK, Hordofa LO, Ayana DA, et al. Prevalence of Escherichia coli O157: $\mathrm{H} 7$ and associated factors in under-five children in Eastern Ethiopia. PLoS One. 2021;16:e246024. doi:10.1371/ journal.pone. 0246024 
14. Mulatu G, Beyene G, Zeynudin A. Prevalence of Shigella, Salmonella, and Campylobacter species and their susceptibility patterns among under-five children with diarrhea in Hawassa town, South Ethiopia. Ethiop J Health Sci. 2014;24:101. doi:10.4314/ejhs.v24i2.1

15. Yemane G, Mulaw G, Gaim T. Prevalence and antimicrobial susceptibility of Salmonella species in diarrheal children under five years of age in Bahir Dar town, Ethiopia. Int J Int Sci Inn Tech Sec. 2014;3:12-17.

16. Beyene G, Tasew H. Prevalence of intestinal parasite, Shigella and Salmonella species among diarrheal children in Jimma health center, Jimma southwest Ethiopia: a cross-sectional study. Ann Clin Microbiol Antimicrob. 2014;13:1-7. doi:10.1186/1476-0711-13-10

17. Wagi T. Prevalence and Antibiotic Resistance of Enteric Bacterial Pathogens Isolated from Childhood Diarrhea in Ambo Town Public Health Institutions [MSc thesis]. College of health science Addis Ababa University; 2015.

18. Lorino T, Daudin -J-J, Robin S, et al. Factors associated with time to neonatal diarrhoea in French beef calves. Prev Vet Med. 2005;68:91-102. doi:10.1016/j.prevetmed.2004.11.013

19. Black RE, Cousens S, Johnson HL, et al. Global, regional, and national causes of child mortality in 2008: a systematic analysis. Lancet. 2010;375:1969-1987. doi:10.1016/S0140-6736(10)60549-1

20. CSA. Basic Data on Agricultural Resources, Development Potentials, and Constraints. Ethiopia: WZA Department of Agricultural Development (WZADAD); 2015:4-44.

21. Quinn P, Markey B, Carter M, et al. Veterinary Microbiology and Bacterial Disease. London: Black Well Science; 2002:1-648.

22. International Organization for Standardization. Microbiology of Food and Animal Feeding Stuffs- Horizontal Method for the Detection of Escherichia Coli O157. 1st ed. Geneva, Switzerland: International Organization for Standardization; 2001. ISO 16654:2001

23. Sagar VA, Davies EJ, Briscoe S, et al. Exercise-based rehabilitation for heart failure: systematic review and meta-analysis. Open Heart. 2015;2:e000163. doi:10.1136/openhrt-2014-000163

24. Stipp DT, Barry AF, Alfieri AF, et al. Frequency of BCoV detection by a semi-nested PCR assay in faeces of calves from Brazilian cattle herds. Trop Anim Health Prod. 2009;41:1563-1567. doi:10.1007/ s11250-009-9347-2

25. Nguyen RN, Taylor LS, Tauschek M, et al. Atypical enteropathogenic Escherichia coli infection and prolonged diarrhea in children. Emerg Infect Dis. 2006;12:597. doi:10.3201/eid1204.051112

26. Mandomando IM, Macete EV, Ruiz J, et al. Etiology of diarrhea in children younger than 5 years of age admitted in a rural hospital of southern Mozambique. Am J Trop Med Hyg. 2007;76:522-527. doi:10.4269/ajtmh.2007.76.522
27. Ansari S, Sherchand J, Parajuli K, et al. Bacterial etiology of acute diarrhea in children under five years of age. $J$ Nepal Health Res Counc. 2012;10(22):218-223.

28. Shah M, Kathiiko C, Wada A, et al. Prevalence, seasonal variation, and antibiotic resistance pattern of enteric bacterial pathogens among hospitalized diarrheic children in suburban regions of central Kenya. Trop Med Health. 2016;44:1-8. doi:10.1186/s41182-016-0038-1

29. Ugwu M, Edeani G, Ejikeugwu C, et al. Antibiotic susceptibility profile of Escherichia coli and Salmonella causing childhood diarrhoea in Awka Municipality, South-Eastern Nigeria. Clin Microbiol. 2017;6:2.

30. Shetty VA, Kumar SH, Shetty AK, et al. Prevalence and characterization of diarrheagenic Escherichia coli isolated from adults and children in Mangalore, India. $J$ Lab Physicians. 2012;4:24. doi:10.4103/0974-2727.98666

31. Moyo SJ, Gro N, Matee MI, et al. Age specific aetiological agents of diarrhoea in hospitalized children aged less than five years in Dar Es Salaam, Tanzania. BMC Pediatr. 2011;11:1-6. doi:10.1186/1471-243111-19

32. Sherchand JB, Yokoo M, Sherchand O, et al. Burden of enteropathogens associated diarrheal diseases in children hospital, Nepal. Sci World. 2009;7:71-75. doi:10.3126/sw.v7i7.3830

33. Edward A, Dam K, Chege J, et al. Measuring pediatric quality of care in rural clinics-a multi-country assessment-Cambodia, Guatemala, Zambia, and Kenya. Int J Qual Health Care. 2016;28:586-593. doi:10.1093/intqhe/mzw080

34. Radostits O, Gay C, Hinchcliff K, et al. A textbook of the diseases of cattle, sheep, goats, pigs, and horses. In: Veterinary Medicine. 10th ed. London, UK: Bailliere, Tindall; 2007:1576-1580.

35. Aiello AE, Coulborn RM, Perez V, et al. Effect of hand hygiene on infectious disease risk in the community setting: a meta-analysis. $\mathrm{Am}$ J Public Health. 2008;98:1372-1381. doi:10.2105/AJPH.2007.124610

36. Sylvester W, Amadi V, Hegamin-Younger C, et al. Occurrence of antibiotic-resistant Escherichia coli in green iguanas (Iguana iguana) in Grenada, West Indies. Int J Vet Med. 2014;2014:1-8.

37. Kageni KL. Diarrhoea Morbidity and Nutritional Status Among Pre-School Children of Hawking Mothers in Nairobi City Markets, Nairobi County, Kenya [MPH Thesis]. Kenyatta University; 2011.

38. Abdullahi M. Incidence and antimicrobial susceptibility pattern of Salmonella species in children attending some hospitals in Kano metropolis, Kano state-Nigeria. Bayero J Pure Appl Sci. 2010;3. doi:10.4314/bajopas.v3i1.58787
Research and Reports in Tropical Medicine

\section{Publish your work in this journal}

Research and Reports in Tropical Medicine is an international, peerreviewed, open access journal publishing original research, case reports, editorials, reviews and commentaries on all areas of tropical medicine, including: Diseases and medicine in tropical regions; Entomology; Epidemiology; Health economics issues; Infectious disease; Laboratory science and new technology in tropical medicine;
Parasitology; Public health medicine/health care policy in tropical regions; and Microbiology. The manuscript management system is completely online and includes a very quick and fair peer-review system. Visit http://www.dovepress.com/testimonials.php to read real quotes from published authors. 